\title{
An Overview of Cloud-Based Decision Support Applications and a Reference Model
}

\author{
Shashidhar KAPARTHI*, Arti MANN, Daniel J. POWER \\ University of Northern Iowa, College of Business Administration, Cedar Falls, IA 50614, USA \\ shashi.kaparthi@uni.edu (*Correspondingauthor),arti.mann@uni.edu,daniel.power@uni.edu
}

\begin{abstract}
Major shifts have occurred in the past 70 years in the deployment of decision support applications. Now it is possible to deploy innovative and traditional Decision Support Systems (DSS) and decision algorithms using Cloud architectures and technologies. Cloud deployment with hand-held, mobile-device platforms is encouraging decision support experimentation and innovation. This survey article emphasizes the-how, especially the architecture, the-what, the-who, the-when, and thewhy of building Cloud-based decision support and decision automation. To assist in conceptualizing cloud-based decision support and analytics, and to facilitate easier understanding and communication, a hierarchical reference model is presented using multiple perspectives. Additionally, the proposed decision support reference architecture model is used to assess cloudbased decision support systems from the prior literature.
\end{abstract}

Keywords: Business analytics, Cloud computing architecture, Cloud-based decision support reference model, Decision support systems.

\section{Introduction}

Cloud technology has evolved from distributed, grid, and utility computing. Cloud computing is a distributed computing paradigm that enables access to virtualized resources and tools including computers, networks, storage, development platforms, and applications (Mell \& Grace, 2009). Cloud computing is one of the fastest-growing innovative technologies and it is predicted that the worldwide public cloud service market will grow from $\$ 182.4 \mathrm{~B}$ in 2018 to $\$ 331.2 \mathrm{~B}$ in 2022, attaining a compound annual growth rate (CAGR) of 12.6\% (Columbus, 2019). Under the umbrella of cloud computing, the three most common service models are Infrastructure as a Service (IaaS), Platform as a Service (PaaS), and Software as a Service (SaaS). These three service models offer a number of potential advantages including reduced costs, omnipresent services, collaborative support, on-demand access to computing resources, and simplified operations (Armburst et al., 2010). The potential value of cloud has encouraged firms to deploy a variety of cloud-based services supporting novel business models. Today, implementing cloud-based computing is one of the leading strategies for creating competitive differentiation of a firm.

Cloud-based decision support and analytics have been used in several domains including financial services, e-business, and supply chains. Within these domains, there is a large variation in the nature and type of the provided decision support, and significant variations in data collection techniques, data collection devices, modelling techniques, infrastructure, output devices, output characteristics, and user characteristics. Given the complexity associated with the above-mentioned domains, conceptualizing and understanding cloud-based decision support and analytics are important tasks. This article proposes a reference model that uses a "divide and conquer" philosophy. Multiple perspectives or lenses are applied to create the proposed reference model. Cloud-based decision support and analytics are examined using an actor lens, a primary driver lens, and an infrastructure lens. Using multiple perspectives allows deeper understanding and facilitates future innovative and creative decision support uses.

The remainder of this article is organized as follows: Section 2 summarizes background on decision support architectures. Section 3 discusses the literature review methodology, defines cloud-based decision support, and discusses the cloud-based decision support and analytics architectures in the context of the prior literature. Section 4 lays out the different perspectives or lenses and presents the proposed reference model. Section 5 categorizes the prior literature based on the proposed reference model and Section 6 draws major conclusions.

\section{Background on Decision Support Architectures}

During the past several decades, the cost of computer and information technology has decreased exponentially. Data storage cost per GB has decreased from over $\$ 1$ million per GB 
in 1966 to $\$ 0.02$ per GB in 2017 (Lucas, 2017). Further, the cost of bandwidth has gone down from $\$ 9.01$ per Mbs in 2006 to $\$ 0.89$ per Mbs in 2016 (NCTA, 2019). During this time frame computer systems evolved from stand-alone mainframe computers to personal computers, to networked computers, to inter-networked computers, and mobile devices. Mainframe computers also evolved into client-server systems, then webbased systems, and now cloud-based systems.

Computing evolution has resulted in several generations of architectures for supporting decision-making and analytics in organizations. An architecture for a computerized decision support system documents the plan for deploying the components of the envisioned DSS. These include Mainframe, Time-sharing, Distributed, Web-based, Mobile-based, and Cloud-based architectures. Table 1 summarizes different generations of architectures identified by Power (2018).

Table 1. Decision Support Architecture Generations

\begin{tabular}{|c|c|}
\hline Generation & Category \\
\hline 1.0 & Mainframe \\
\hline 2.0 & Time-Sharing \\
\hline 3.0 & $\begin{array}{c}\text { Distributed: network, bridge, sandwich, } \\
\text { and tower }\end{array}$ \\
\hline 4.0 & $\begin{array}{c}\text { Client Server/Web-based: distributed } \\
\text { dialogue, remote dialogue, distributed } \\
\text { model, distributed data, remote data, and } \\
\text { stand-alone }\end{array}$ \\
\hline 4.5 & Mobile-based \\
\hline 5.0 & Cloud-based \\
\hline
\end{tabular}

\section{Generation 1: Mainframe}

Mainframe hardware was rudimentary using vacuum tubes, the operating systems were elementary, the software was specialized, and decision support was included as part of operational tasks like payroll, and users needed technical expertise.

\section{Generation 2: Time-Sharing}

Time-Sharing was a multi-programming and multitasking architecture that provided a computing resource to many users concurrently. This architecture was used for many tasks including decision support in the 1960s and 1970s.

\section{Generation 3: Distributed}

Sprague \& Carlson (1982) defined four components of a DSS technology framework as dialogue management, database management, model base management, and DSS architecture. They identified four architectures: 1) DSS Network, 2) DSS Bridge, 3) DSS Sandwich, and 4) DSS Tower. The DSS Network has multiple dialogue, modelling and database components that are interconnected. The Bridge has a standard interface with local dialogue and modelling components that link to remote modelling and database components. A Sandwich architecture has a single dialogue and database component, but with multiple model components linked by the architecture. Finally, the Tower includes more vertical components or tiers with data extraction tools integrating diverse data base components. The rest of the Tower architecture is similar to the Network architecture structure.

\section{Generation 4: Client Server/Web-based}

Power \& Kaparthi (1998) identified six DSS architectures subtypes: 1) distributed dialogue, 2) remote dialogue, 3) distributed model, 4) distributed data, 5) remote data, and 6) standalone. Distributed dialogue is basically a thinclient web architecture. The remote dialog is a more traditional thick-client application. In the distributed model, the application software on the client expands, and model capabilities are distributed. The distributed data architecture requires accessing data across the network. With a remote data architecture, some data is downloaded to the client for faster processing. Finally, a standalone architecture has the entire DSS application on a stand-alone computer with no provision for network access to server-based components.

\section{Generation 4.5: Mobile}

According to Power (2013), mobile decisionsupport uses wireless technology and portable computing devices to provide interactive computer-based systems to help decisionmakers use data, documents, knowledge, and models to identify and solve problems, complete decision process tasks, and make decisions. Mobile decision support also includes alerts and information pushed to a user based on location.

\section{Generation 5: Cloud}

Cloud-based DSS uses a cloud computing architecture to deliver decision support applications (Power, 2012). A well-designed cloud that uses redundancy can be reliable, secure, and 
suitable for business applications. Using a cloud to deliver decision support can reduce capital expenses and operating costs (Irvine, 2012). Other benefits claimed are agility, accessibility to software and device and location independence.

\section{Literature Review}

A search in the ABI/INFORM database of periodicals was conducted for all the articles with titles that included the 3 terms "cloud, decision, and support. In addition to relevant articles for this study, the search also resulted in articles that were describing decision support needed for migration to cloud computing environments. After removing such articles from further analysis and tabulation, there were a total of 30 articles relevant to this analysis. Table 2 below summarizes the reviewed articles.

Table 2. Articles Reviewed

Notation: Cloud-based Decision Support provided: D: Data-driven; M: Model-driven; C: Communicationdriven; K: Knowledge-driven; O: Document-driven

\begin{tabular}{|c|c|c|c|c|c|c|c|}
\hline & Authors & D & $\mathbf{M}$ & C & $\mathbf{K}$ & $\mathbf{O}$ & Domain/ Environment \\
\hline 1 & Jayalakshmi \& Gomathi (2018) & & & $\mathrm{x}$ & & & Healthcare \\
\hline 2 & Mercier-Laurent et al. (2018) & & & & $\mathrm{x}$ & & Industrial Design and Energy \\
\hline 3 & Wan et al. (2018) & & & & $\mathrm{x}$ & & Material Handling \\
\hline 4 & Rupnik et al. (2019) & $\mathrm{x}$ & $\mathrm{x}$ & & & & Agriculture \\
\hline 5 & Heilig et al. (2017) & & $\mathrm{x}$ & & & & Logistics \\
\hline 6 & Singh (2017) & & & $\mathrm{x}$ & & & Water Management \\
\hline 7 & Eskelinen et al. (2017) & $\mathrm{x}$ & $\mathrm{x}$ & $\mathrm{x}$ & & & Environmental Monitoring \\
\hline 8 & Hill \& Böse (2017) & & $\mathrm{x}$ & & & & Transportation \\
\hline 9 & Bock et al. (2017) & $\mathrm{x}$ & & & & & Search \& Rescue \\
\hline 10 & Choi \& Lambert (2017) & $\mathrm{x}$ & & & & & Risk Analysis \\
\hline 11 & Gupta et al. (2017) & & & & $\mathrm{x}$ & & Healthcare \\
\hline 12 & Helo \& Hao (2017) & & $\mathrm{x}$ & $\mathrm{x}$ & & & Manufacturing \\
\hline 13 & Lee (2017) & $\mathrm{x}$ & $\mathrm{x}$ & & $\mathrm{x}$ & & Retail \\
\hline 14 & Kumar et al. (2016) & $\mathrm{x}$ & & & & & Manufacturing \\
\hline 15 & Chapron (2015) & & $\mathrm{x}$ & & & & Wildlife Management \\
\hline 16 & Lee et al. (2016) & & $\mathrm{x}$ & & $\mathrm{x}$ & & Franchise Inventory \\
\hline 17 & Lauras et al. (2015) & & $\mathrm{x}$ & & & & Crisis Management \\
\hline 18 & Depeige \& Doyencourt (2015) & & & & $\mathrm{x}$ & $\mathrm{x}$ & General \\
\hline 19 & Mackay et al. (2015) & $\mathrm{x}$ & $\mathrm{x}$ & & $\mathrm{x}$ & & Environmental Policy \\
\hline 20 & Benatia et al. (2015) & & $\mathrm{x}$ & $\mathrm{x}$ & & & Urban Planning \\
\hline 21 & O'Flaherty \& Heavin (2015) & & $\mathrm{x}$ & & $\mathrm{x}$ & & Consumer Behavior \\
\hline 22 & Guo et al. (2015) & & $\mathrm{x}$ & & & & Manufacturing \\
\hline 23 & Chichernea (2014) & & $\mathrm{x}$ & $\mathrm{x}$ & & & Smart City Management \\
\hline 24 & Bara et al. (2014) & $\mathrm{x}$ & $\mathrm{x}$ & & & & Energy \\
\hline 25 & Tsiligiridis et al. (2014) & $\mathrm{x}$ & $\mathrm{x}$ & & & & Pest Control \\
\hline 26 & Peng \& Shiang (2014) & $\mathrm{x}$ & & & & & Sustainable Supply Chain \\
\hline 27 & Guo et al. (2014) & & $\mathrm{x}$ & & & & Manufacturing \\
\hline 28 & Thomas et al. (2013) & & $\mathrm{x}$ & & & & Hospital Administration \\
\hline 29 & Demirkan \& Delen (2013) & $\mathrm{x}$ & $\mathrm{x}$ & $\mathrm{x}$ & $\mathrm{x}$ & $\mathrm{x}$ & General \\
\hline 30 & Bellini et al. (2012) & & & & & $\mathrm{x}$ & Healthcare \\
\hline
\end{tabular}


Next, the articles were read and categorized by content. The four article categories are 1) real time data focused, 2) visualization based, 3) end user focused, and 4) components of cloud-based architectures. Some of the major articles in each category are summarized below.

\subsection{Real Time Data Focused}

Eskelinen et al. (2017) proposed a system where modern sensor technologies with connections to cloud-based data collection services were used for monitoring and collecting environmental data. They applied a four-stage innovation process for industry, which included context definition, idea generation, and selection, and produced multicriteria decision support data to help the design of the business model. According to the authors, environmental monitoring typically combines many data sampling sources (e.g., from water, air, or soil) with multiple methods of measurement. Continuous monitoring has made it possible to collect data almost constantly in real-time, with multiple variables being measured simultaneously and stored on cloud-based infrastructure.

Guo et al. (2014) address the order tracking and allocation problem in an apparel manufacturing environment with multiple plants. A cloud-based intelligent decision system was developed to tackle this problem and track remote production orders. It employed computational intelligence techniques to generate effective order allocation solutions each plant. In their system, radio frequency identification and cloud computing technologies were used to capture real-time production records. The system implementation resulted in reductions in production costs and increases in production efficiency.

Thomas et al. (2013) implemented and hosted a prototype real-time bed-assignment solution as a cloud-based application for Mount Sinai Medical Centre in New York. The authors argue that bed management is an important function of any hospital and has a major impact on patient care, patient flow, patient, and staff satisfaction, and ultimately on the hospital's operating margin. Further, a key challenge in bed management is optimizing the bed-assignment process.

\subsection{Visualization Based}

Bock et al. (2017) proposed a visualization system for incident commanders in urban search and rescue scenarios, that supports path planning in post-disaster structures. Their system utilizes point cloud data acquired from unmanned robots and generates assessments of automatically generated paths. As data uncertainty and a priori unknown information make fully automated systems impractical, they present the incident commanders with a set of viable access paths, based on varying risk factors, in a $3 \mathrm{D}$ environment combined with visual analysis tools enabling informed decisionmaking and trade-offs. They describe visualization design considerations for the system and decision support.

\subsection{End User Focused}

Chapron (2015) argues that research in wildlife management increasingly relies on quantitative population models but it is a challenge to have end-users benefit from this research. The author then proposes a new approach, 'wildlife in the cloud,' to enable active learning by practitioners from cloud-based ecological models whose complexity remains invisible to the user. This concept is illustrated by presenting an online decision-support tool for moose management in areas with predators in Sweden. A cloud-app is designed through which users can compare the effects of alternative management decisions that can be used for adjusting their hunting strategy. Further, the dynamic nature of cloud-apps opens the door to different ways of learning, informed by ecological models from which both the users and the researchers can benefit.

O'Flaherty \& Heavin (2015) report a design for a predictive decision support system for customer retention. They argue that the power of propensity scoring based on historical data delivered as a service via cloud computing heralds the availability of capabilities that previously required teams of quantitative specialists to deliver. This experimental predictive analytics platform was developed in conjunction with a statistical software company. In their system, analysis of historical data gives an indication of the predicted future behaviour of magazine subscribers. The key stakeholders who could use the system include the retention manager, the data administrator, and the account manager. The retention manager develops the company's overall retention strategy with the support provided by the system while working closely with the account managers, who are responsible for implementing the strategy. 


\subsection{Components of Cloud-Based Architectures}

Russell et al. (2010) develop a mathematical model for assessing the availability of a cloud-based DSS. They draw distinctions between decision resource availability and system reliability. They conceptualize a hierarchical relationship between several resources needed like data from some storage-system, a network communication medium, an output device, collaborating system users, or even decision-makers themselves. They view a decision resource as a hierarchical structure of interacting functions. This hierarchical structure may have multiple levels and when the resource is a computing device, these levels would encompass hardware, firmware, and software. The underlying concept is that a decision-resource, via its hierarchy, relates to a number of sub-resources at lower levels of the hierarchy. The functions in a resource hierarchy act and interact together to provide the resource at the top of the hierarchy. Upper-level functions depend on lower levels to ensure their reliability and availability. They argue the real benefit of the model may be realized when availability information is extended to the decision maker.

Liu et al. (2011) identify three services as part of an overall DSS, a data service, an information service and an analytics service and several other components. An application programming interface acts as a mechanism to populate source systems with raw data and to pull operational reports. Operational transaction systems run dayto-day business operations and provide source data for the data warehouse and DSS environment. An enterprise application integration/staging area provides an integrated common data interface and interchange mechanism for real-time and source systems. Extract, transform, and load (ETL) processes move source data into the data warehouse and move data from one location to another. Metadata management is part of the data service and it describes the meaning and structure of business data, as well as how it is created, accessed and used. In addition, there is provision for data marts in the cloud that support specific decision and analytical needs and provide business units more flexibility, control, and responsibility.

As seen in Table 1 and the above examples, cloudbased decision support and analytics have been used in several domains of applications including but not limited to logistics, environmental monitoring, search and rescue operations, wildlife management, consumer/buyer behavioural prediction, manufacturing, and hospital administration. The data collection techniques, the data collection devices, the modelling techniques, the infrastructure, the output devices, the output characteristics, the users, the interactions and the nature of decision support are varied too. Given such complexity, a systematic reference model is needed for conceptualizing and understanding these systems. The major focus of this article is to propose an understandable reference architecture model with commonly occurring elements and capabilities.

\section{Proposed Reference Model for Cloud-Based Decision Support and Analytics}

Previous examples of systems and architectures demonstrate the complexity of conceptualizing and understanding cloud-based decision support and analytics. To enable the conceptualization of such a complex phenomenon, a reference model that uses a "divide and conquer" philosophy is proposed. Multiple perspectives or lenses are applied in the present reference model. Cloudbased decision support and analytics are examined using an actor lens, a primary driver lens, and an infrastructure lens. Multiple perspectives allow deeper understanding and facilitate future innovative and creative uses. Further, each of these perspectives is approached in a hierarchical fashion with several levels of increasing detail and focus.

The three lenses capture the breadth, and the levels capture the depth of the concepts. In the present nomenclature, a prefix is used to represent the lens, or the perspective being used; for example, A. is used for the actor lens. The levels are numbered $0,1,2,3 \ldots$ where level 0 is the highest level that provides a birds-eye view of cloud-based decision support and level 1 would zoom in to the next level of detail and so on.

\subsection{Actor Lens}

Design, implementation, and use of cloudbased decision support systems involve multiple organizations and individuals or actors. This reference model from the actors' perspective is shown in Figure 1. The Level 0 conceptualization depicts the relationships, interactions, and coordination between all these actors. This model is structured similarly to the reference model for 
cloud computing from the National Institute of Standards and Technology, U.S. Department of Commerce (Liu et al., 2011). A Cloud-Based decision support and analytics consumer enters a contractual relationship with a provider. For example, an organization (consumer) uses Amazon Web Services (provider) for the design and use of a system. Optionally, the interaction could be with an intermediary who provides value-added services. For example, an organization uses a SaaS application offered by an intermediary who in turn contracts with a provider.

The consumer (A.1) is one of many types: an individual (A.1.1), a team, an organization or a group of organizations. Further, an individual's task within an organization could be operational (A.1.1.1), tactical or strategic. The nature of the provided decision support varies based on the type of task being performed. The teams or groups of users are operating synchronously or asynchronously and are located at the same place or are at different places. Again, the nature of decision support, the technology, and the interactions would vary among these use cases. The domain within the organization provides useful context. Financial applications use a lot of numbers whereas a marketing use case involves more text processing like customer reviews. Lastly, a supply chain is an example of a consumer that involves a group of participating organizations. The provider could be an external organization, a consortium or an internal private cloud. A hybrid provider is another possibility.
Often, the provider has a portal for managing the service with tools for provisioning compute and store. Management tasks like monitoring and billing are also available through these portals. Tools for migrating data and legacy applications as well as educational materials are included. User and identity management with associated credentials, rights, and security provisions allow teams of developers and users proper access. Federated identity management allows users from consumer organizations single-sign-on convenience. Billing can be customized to match the transfer pricing mechanisms prevalent in the consumer organization. In the ZDnet survey of 2019 top cloud providers, Dignan (2019) estimates Amazon Web Services - AWS annual revenue run rate based on latest quarter at $\$ 29.72$ billion, Microsoft Azure annual revenue run rate at $\$ 11$ billion, Google cloud platform's annual revenue run rate at $\$ 4$ billion and Alibaba's annual revenue run rate at $\$ 3.85$ billion. Workday with an annual cloud revenue run rate of $\$ 3$ billion is an example of a cloud intermediary that allows Amazon Web Services - AWS hosting. In addition to hybrid on-premises/off-premises infrastructure, the use of multiple public providers is growing. According to the survey, 97 percent of respondents reported their companies to use Amazon Web Services - AWS, but 35 percent also said they actively use Azure too. Twentyfour percent use Amazon Web Services - AWS and Google Cloud Platform together.

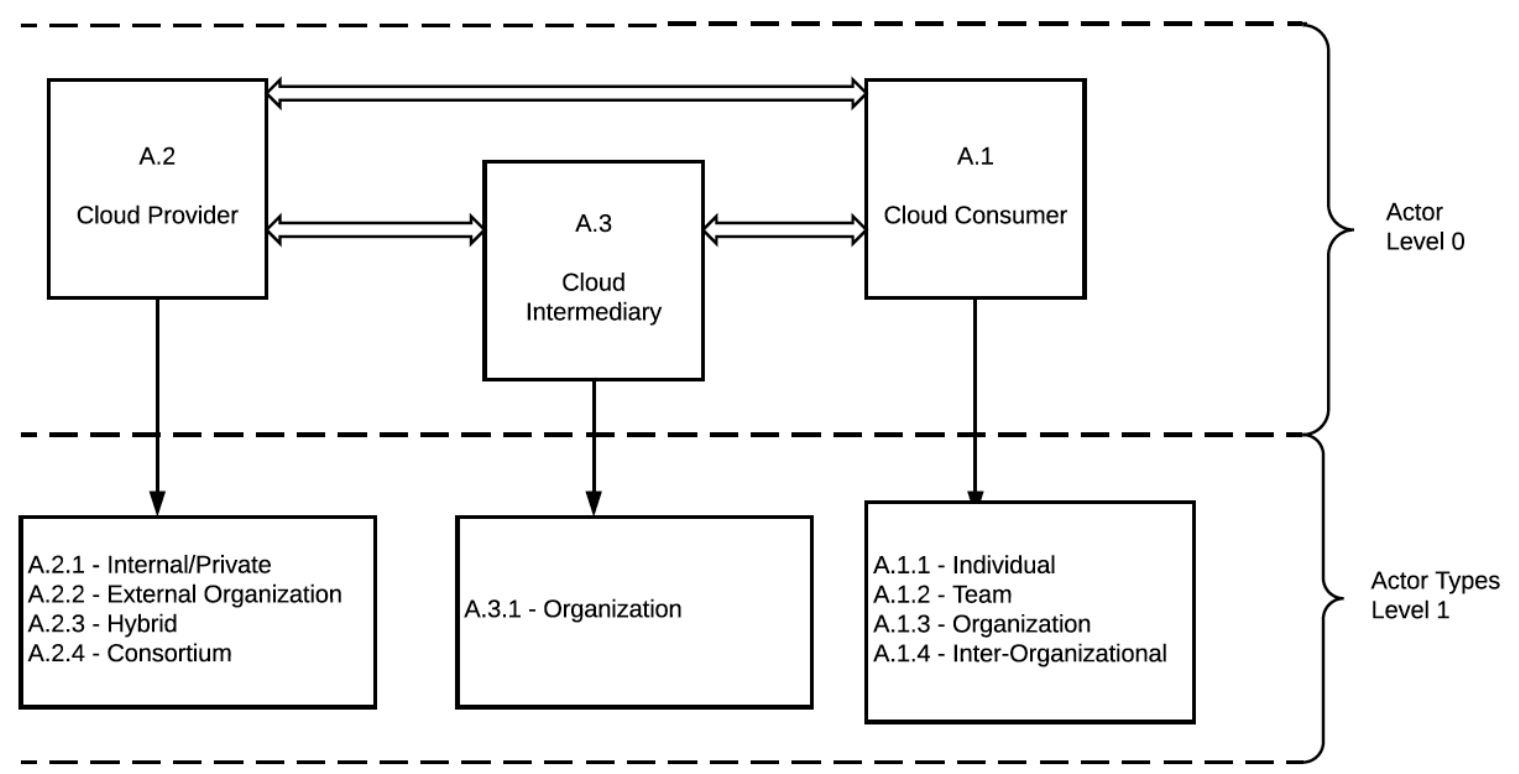

Figure 1. Reference Model - Actor Lens 


\subsection{Primary Decision Driver Lens}

Decision support research has a rich history spanning several decades. Power (2001) reviewed the DSS research and classified the decision support provided as being primarily driven by one or more of several factors. He classified decision support systems into data-driven, modeldriven, communication-driven, knowledgedriven and document-driven systems. Using the lens of the primary driver for the provision of decision support, Figure 2 presents the proposed reference model for cloud-based decision support and analytics. There is also a possibility of overlap between data-driven, model-driven, communication-driven, knowledge-driven and document-driven features.

The exponential growth in the amount of data being collected and stored has been the subject of mainstream media, practitioners, and researchers recently. Big data and analytics are common terms now. Cloud-based data-driven systems (D.1) are especially suited for storing large amounts of data with on-demand, pay-as-yougo storage and services. Application software to visualize this data provides decision support to users by allowing management reporting, data exploration and exception identification, ABC analysis, executive dashboards with KPI tracking, as well as a graphical presentation of data and trends with colours, fonts, animations, and other visual elements. Graphical tools allow a simplified display of data with minimal clutter to facilitate business insight.

Correlations between outcomes of interest and independent variables can be examined to facilitate hypothesis formulation and mental model building. Efficiency and speed of visualization are additional benefits provided by massively parallel processing in cloud clusters. Good visuals enable meaningful storytelling. By allowing easy integration of data from multiple sources with limited technical database skills requirements, users are able to create visualizations and get insight with little help from Information Technology - IT personnel.

Model-driven decision support (D.2) is primarily facilitated by use of mathematical and other types of models. Spreadsheets (Kaparthi \& Power, 2002) allow mathematical models to be created and users can conduct what-if analyses and goal seeking to help facilitate decision-making. For example, once a model is constructed, a manager could ask a question like "what if I increase my advertising spend by $10 \%$ on Facebook, how might it impact the sales?" Model-driven decision support relies on research contributions from the disciplines of management science and operations research. Linear programming, nonlinear programming,

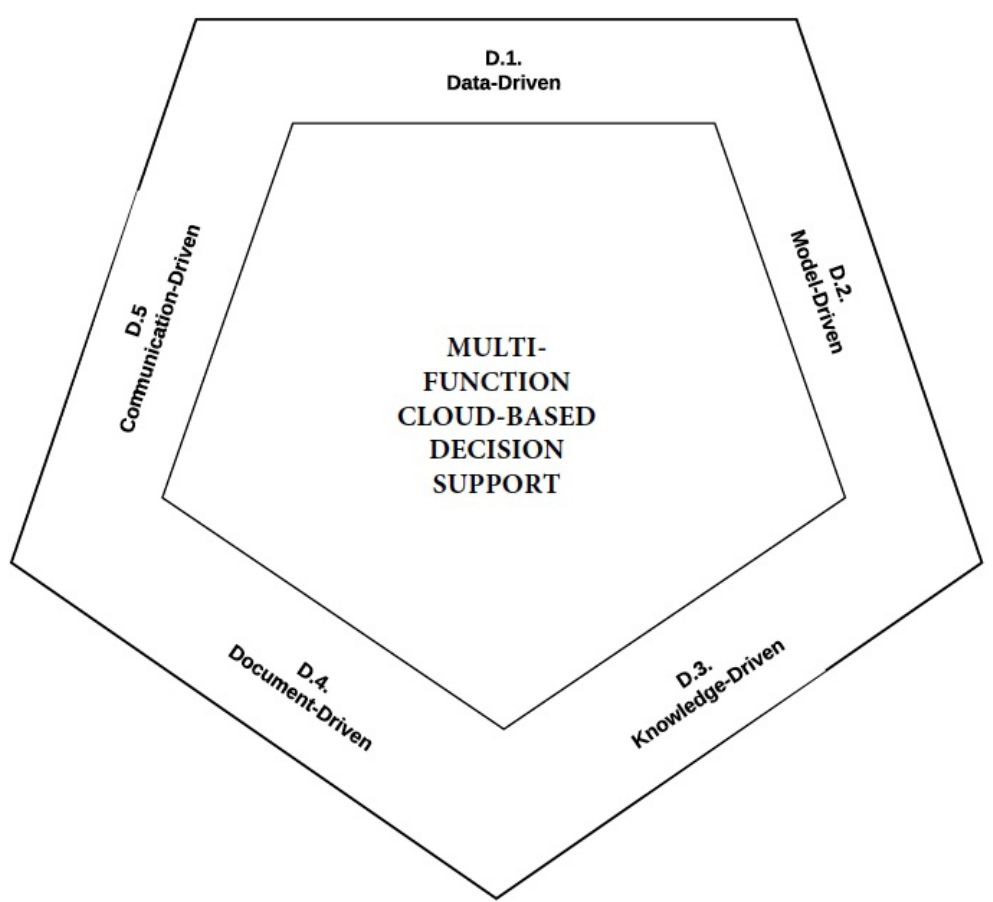

Figure 2. Reference Model - Primary Decision Driver Lens 
integer, and binary programming as well as multicriteria decision-making have many applications in business organizations.

Handling uncertainty is done through stochastic modelling as well as Monte-Carlo simulations. Computer-aided design and modelling, simulation of effects of operating conditions through finite element methods, and augmented reality and virtual reality allow for visualization of products and facilities prior to them being built. Automated decision algorithms can also be deployed in the cloud. Cloud-based systems allow for real-time optimization of models to enable innovative use cases like when Uber solves multiple shortest path problems when a customer requests a ride to find the closest drivers available.

A major way in which knowledge-driven decision support (D.3) is different from the others is that the system can suggest or recommend a course of action to managers. These systems have specialized problem-solving expertise. This expertise consists of knowledge about a particular domain, understanding of problems within that domain, and skill at solving some of these problems. A future step in knowledge driven DSS is to augment decision maker intelligence and problem-solving capabilities by providing artificial cognitive systems (Filip, 2020; Siddike et al., 2018).

A related concept is Data Mining. It refers to a class of analytical applications that search for hidden patterns in a database. Data mining is similar to machine learning and is the process of sifting through large amounts of data to produce data content relationships. Analytics applies these data mining concepts and other tools.

According to Power et al. (2018), business analytics is a "systematic thinking process that applies qualitative, quantitative, and statistical computational tools and methods to analyse data, gain insights, inform, and support decisionmaking. Any particular analysis may use a variety of techniques including diagnostic, predictive, prescriptive, and optimization models."

Document-driven decision support (D.4) builds on document management systems that were designed to make organizations go paperless by tracking, storing, archiving, and retrieving documents based on keywords, indexing, and content. With the rapid growth in web and social media, companies can now access an enormous amount of text with mentions, comments, and reviews of their products and other happenings. Customers' emails and chats are other important sources. Document-driven decision support is provided by several tools that can search through this large amount of unstructured data to find documents of interest.

Automated summarizations, classification, sentiment analysis, natural language processing, and bibliometric \& lexical analysis allow decision-makers to listen to their customers and other stakeholders. Word clouds and other visualizations provide insight into the situation. Optical Character Recognition (OCR) is easily implemented in the cloud. For example, Google Cloud Vision Application Programming Interface - API has a Detect Text OCR feature. Domainspecific tools are also being designed to deal with vocabulary related to certain professions. For example, Amazon Comprehend Medical is useful for extracting complex medical information from unstructured text. This service can identify medical information, such as medical conditions, medications, dosages, strengths, and frequencies from a variety of sources like doctor's notes, clinical trial reports, and patient health records.

Communications-driven decision support (D.5) has its roots in research about group decision support systems. It includes communication, collaboration and decision support technologies that groups of people use together (Filip et al., 2017). Cloudbased systems are well suited for communicationdriven decision support due to the need for coordination, collaboration, planning, assessment, decision-making, consensus generation between team members in geographically distributed global organizations. Such systems allow users the use of communications as well as decision models.

Support for electronic communication, messaging, scheduling, document sharing, and other group productivity activities enhance decision support. As mentioned in the subsection about the actor lens, teams or groups of users may be operating synchronously or asynchronously and are located at the same place or are at different places. Massey (2008) lists tools that are relevant to the present context too. Support for synchronous same-place situations is provided through brainstorming, voting, prioritization, and presentation tools. Support for synchronous different-place situations

https://www.sic.ici.ro 
is provided through audio-video conferencing, chat, instant messaging, screen sharing and co-editing. Editing a shared Google document synchronously is an example of such support provided by cloud-based systems.

Workflow and e-signatures formalize business processes. For example, Slack is a cloudbased collaboration hub that has gained a lot of popularity recently. Asynchronous situations can benefit through such tools too.

\subsection{Services Lens}

Next, the service lens perspective for Cloud-based decision support and analytics proposed in this paper is presented. This proposed reference model is partially based on the Cloud Standards Customer Councils' (CSCC) reference architecture for the traditional analytics production environment (Beradi et al., 2015). The present reference model takes into consideration the provider cloud, enterprise network, various deployment options, analytical services, and multi-channel delivery. As shown in Figure 3, there are five main components of the reference model as well as the various deployment options and data sources. The following sections describe the main components of the proposed model.

\section{S.1 Data Sources}

Large volumes of data come from a variety of sources over the Internet to the cloud infrastructure. These sources include both external and internal sources. The external sources are generally public data extracted from various sources outside of the organization such as websites, mobile devices, audio and video, thirdparty aggregators, machines and sensors, and social media. Internal data is retrieved from all functional areas of an organization.

\section{S.2 Integration Services}

The cloud service provider uses integration services to organize data and information collected from various sources into data repositories. Cloud integration solutions include the discovery of data sources, cleansing, transforming and monitoring data. Different methods such as Extract Transform Load - ETL, event-based processing, capturing the change of data with replication, and streaming computing are used. The primary goal is to create and organize data repositories (using enterprise metadata definitions) where analytics can be performed to deliver actionable insights.
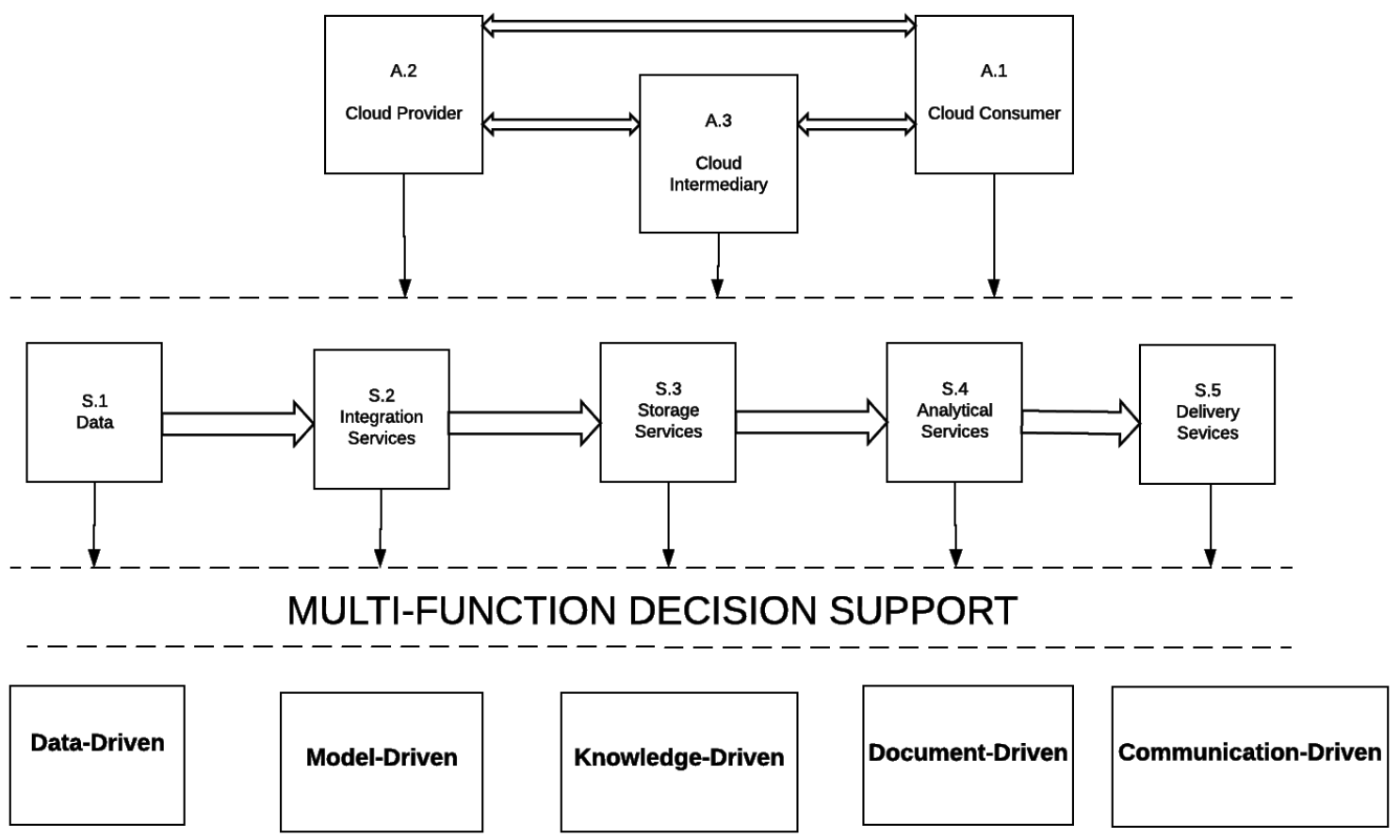

Figure 3. Reference Model - Services Lens 


\section{S.3 Storage Services}

Storage services in the cloud are provided through Data-as-a-Service (DaaS), Infrastructure-as-aService (IaaS) and Replication-as-a-Service. DaaS builds a layer of abstraction so that organizations can access data without knowing where data resides. IaaS provides processors, hardware and networking capabilities to store big data. This model is often implemented via Virtualization to allow multiple users to work concurrently. The cloud provider offers a cost-effective, highly scalable and efficient Replication-as-a-Service for backing up data so that information can be recovered anytime in case of a system failure or in the event of downtime.

\section{S.4 Analytics Services}

Using virtualized analytical and information services provide the ability for all users in an organization to perform analysis on the datasets that they are interested in analysing (Demirkan \& Delen, 2013). Analytics services provide software tools, templates and deployed analytics applications for use by an organization. Some of the examples of such tools include a variety of software tools, analytics discovery and exploration (for building new analytical models), dashboards, and deployed analytics applications (for predictive analytics, content analytics, planning, and forecasting) (Beradi et al., 2015).

The core concept of information services is to make consistent data available for any application. Information services provide a "single version of the truth" and make data accessible at all times and to all applications. Information services minimize the cost and time by establishing a single, trusted source so that it is possible to set up a separate consumer of data in a separate application with little effort (Demirkan \& Delen, 2013).

\section{S.5 Multi-Channel Delivery Options}

The cloud service provider delivers the business analytics data, results and solutions over multiple channels, including stationary and mobile channels, such as - desktop, laptops, mobile phones, tablets, email, printers, etc.

The deployment of analytics and BI in the cloud is complex. With cloud computing generally, complexity exists because of multiple deployment models (e.g., public cloud, private cloud, hybrid cloud, and community cloud), service options (e.g., SaaS, PaaS, IaaS) and utilization choices (fully cloud-based, hybrid mix of cloud and legacy system, fully legacy system-based, etc.).

\section{Application of the Proposed Reference model to Past Works}

Benatia et al. (2015) propose a cloud-based multiple criteria decision support system for selecting urban housing sustainable development projects in order to help the decision-makers to choose the best urban project with conflicting criteria. Their DSS is deployed on a CloudBees Cloud platform and managed by the OpenStack infrastructure. According to the authors, this cloudbased DSS had significant advantages: it reduced the deployment and processing time, ameliorated the communication and the cooperation between the decision-makers, facilitated the accessibility, and decreased the cost. The DSS was built on the Cloud Computing architecture with three layers and included a multiple criteria decision-making method as well as the procedure of negotiation in order to help the decision-makers to select the best urban project. This example would be categorized as incorporating both model-driven and communication-driven cloud-based DSS features within the urban planning domain.

Gupta et al. (2017) propose an intelligent decision support model that can aid medical experts in predicting heart disease based on the historical data of patients. Various machine learning algorithms were implemented on the heart disease dataset to predict accuracy for heart disease occurrence. Naïve Bayes had been selected as an effective model because it provided the highest accuracy followed by AdaBoost and boosted tree. Further, when ensembled, these 3 models increased the overall accuracy. The experimental results were evaluated using over 10,000 instances that clearly validated the maximum accuracy through ensembling and minimum execution time in a cloud environment. This example might be categorized as incorporating knowledge-driven cloud-based DSS features within the healthcare domain.

Hill \& Böse (2017) present an innovative decision support system that simultaneously provides predictive analytics to logistic nodes as well as to collaborating truck companies. They suggest a flexible cloud-based service that incorporates an advanced forecasting engine based on artificial intelligence capable of providing individual predictions for users on all planning levels. Their 
system provided forecasted truck arrival rates to the nodes and predicted truck gate waiting times at the nodes to the truck companies based on historical data, economic and environmental impact factors. Based on the expected workloads, the node personnel and machinery could be planned more efficiently. One would categorize this example as a cloud-based DSS using modeldriven features in the transportation domain.

Rupnik et al. (2019) describe a system named AgroDSS for farm management decision support that bridges the gap between agricultural systems and decision support methodology. The system integrates into existing farm management information systems and provides a cloud-based decision support toolbox, allowing farmers to upload their own data, utilize several data analysis methods and retrieve their outputs. The implemented tools include predictive modelling with an explanation, accuracy evaluation, time series clustering and decomposition, and structural change detection. They can help users make predictions for simulated scenarios and better understand the dependencies within their domain. Further, the authors applied the AgroDSS system on a case study of pest population dynamics. One would categorize this system as a cloud-based DSS with data-driven and model-driven features in the agriculture domain.

Jayalakshmi \& Gomathi (2018) proposed a system to report the progress of the elderly in an appropriate manner with the help of the technology used in the healthcare system and integrate the report of progress to the remote caretakers employing smartphones and videos. This advancement in medical informatics has been done to monitor the health of the patients and provide the details to the caretakers, who are nearby the remote areas. Medical informatics comprises a huge number of medical resources to enhance storage, retrieval of health data, and usage of these resources in healthcare. Their system requires certain sensors which are of low cost, certain electronic devices, and smartphone for the communication purpose. Due to the condition monitoring of patients in real-time, the caretaker can provide suggestions regarding diagnosis through a video conference. Abnormalities are identified at an early stage and increase the physical and mental health of patients. One would categorize this application as communication-driven cloud-based DSS in the healthcare domain.
Helo \& Hao (2017) propose a cloud-based production planning system for sheet metal processing. According to the authors, cloud manufacturing has the potential to offer decision support as a service and medium of communication in production planning and control. Further, many production planning and control problems are essentially optimization problems, where the objective is to develop a plan that meets the demand at minimum cost or maximum profit. Because the underlying optimization problem will vary in the different business and operation phases, it is important to think about it in a dynamic mechanism and in a number of interlinked sub-problems at the same time and to solve these problems and produce collaboration across the supply chain. This application is categorized as a communicationdriven and model-driven cloud-based decision support system in the manufacturing domain.

Lee (2017) suggests that in Retail 4.0, Omnichannels require seamless and complete integration of all available channels for purchasing and that the diversification of channels not only diversifies data sources but also rapidly generates an enormous amount of data. Big data analytics can extract meaningful knowledge for decisionmaking. The author then proposes a genetic algorithm-based optimization model to support anticipatory shipping which is getting more popular to ensure fast product delivery. The goal of the system is to predict when a customer will make a purchase and then begin shipping the product to the nearest distribution centres before the customer places the orders online. The big data generated from all channels are stored in the cloud. Future purchases are predicted by using cluster-based association rule mining in terms of If-Then prediction rules. The algorithm considers transportation cost, traveling distance and the confidence of prediction rules in the optimization process. This application is a cloud-based DSS with data-driven, knowledge-driven and modeldriven decision support features.

All the 30 studies that resulted from the search described earlier in the second section are presented in Table 2. As seen in Table 2, articles relevant to cloud-based DSS started appearing in the academic literature in 2012. Those articles described several domains of application. The most frequently provided cloud-based decision support was model-driven, then data-driven, followed by knowledge-driven, communication-driven 
and lastly document-driven. The most popular application domain has been manufacturing, and healthcare is the second. Over the time period in the review, a broadening of domains as well as an increase in the number of applications are seen.

\section{Conclusion}

As computer and information technology evolved so did the architectures for designing applications that provide decision support. There have been five generations of such architectures, starting with the first generation that included the use of a mainframe computer, the second generation that required time-sharing, the third generation articulated by Sprague \& Carlson (1982), the fourth generation that was client-server and web-based, generation 4.5 that used mobile devices to generation 5.0 that expanded the technology used to include cloudbased decision support and analytics.

This article presents a multi-perspective hierarchical reference architecture model for conceptualizing cloud-based decision support and analytics.

Multiple perspectives were used for conceptualizing the breadth and creating a hierarchical approach for conceptualizing the depth of the involved concepts. These systems were examined from an actor lens, a primary-driver lens, and a services' lens. The components involved in each of these perspectives were then explored in a hierarchical fashion by zooming into each one at a time. Finally, several other studies from the prior literature were then categorized according to the primary driver lens in the proposed reference model.

In addition to helping understand the complex cloud computing phenomenon, this reference model can also be used to identify avenues for future decision support research. For example, there is a need for design science research on document-driven cloud-based decision support in law firms and other specialized settings. Another example of a need is extending the limited research that examines business adviser bots that use natural language voice and/or text interfaces to provide conversational decision support.

This hierarchical, three lens, decision support reference architecture model can maximize the impact and facilitate the adoption and understanding of cloud-based decision support and analytics.

\section{REFERENCES}

Amazon.com (2006). Announcing Amazon Elastic Compute Cloud (Amazon EC2) - Beta. Available at: $\quad<$ https://aws.amazon.com/about-aws/whatsnew/2006/08/24/announcing-amazon-elastic-computecloud-amazon-ec2---beta/>, last accessed: 01/26/2021.

Armbrust, M., Fox, A., Griffith, R., Joseph, A. D., Katz, R., Konwinski, A., Lee, G., Patterson, D., Rabkin, A. Stoica, I. \& Zaharia, M. (2010). A View of Cloud Computing, Communications of the ACM, 53(4), 50-58.

Bara, A., Lungu, I., Oprea, S. V., Carutasu, G., Botezatu, C. P. \& Botezatu, C. (2014). Design Workflow for Cloud Service Information System for Integration and Knowledge Management Based in Renewable Energy, Journal of Information Systems and Operations Management, 8, 230-237.

Bellini, P., Bruno, I., Cenni, D., Fuzier, A., Nesi, P. \& Paolucci, M. (2012). Mobile Medicine: Semantic Computing Management for Health Care Applications on Desktop and Mobile Devices, Multimedia Tools and Applications, 58(1), 41-79. DOI: 10.1007/s11042010-0684-y

Benatia, I., Laouar, M. R., Bendjenna, H. \& Eom, S. B. (2015). A Cloud-Based Multi-Criteria Decision
Support System for Selecting Urban Housing Projects, Human Systems Management, 34(2), 119-132.

Berardi, T., Chessell, M., Gupta, M., Kak, A., Kreger, H., Statchuk, C. \& Schalk, K. (2015). Customer Cloud Architecture for Big Data and Analytics, Version 1.1, 1-20. Cloud Standards Customer Council.

Bock, A., Svensson, Kleiner, A., Lundberg, J. \& Ropinski, T. (2017). A Visualization-Based Analysis System for Urban Search \& Rescue Mission Planning Support, Computer Graphics Forum, 36(6), 148-159. DOI: $10.1111 / \operatorname{cgf} 12869$

Chapron, G. (2015). Wildlife in The Cloud: A New Approach for Engaging Stakeholders in Wildlife Management, Ambio, 44, 550-556. DOI: 10.1007/ s13280-015-0706-0

Chichernea, V. (2014). The Use of Decision Support Systems (DSS) in Smart City Planning and Management, Journal of Information Systems \& Operations Management, 8(2), 1-14.

Choi, T. \& Lambert, J. H. (2017). Advances in Risk Analysis with Big Data, Risk Analysis, 37(8), 14351442. DOI: $10.1111 /$ risa. 12859

https://www.sic.ici.ro 
Columbus, L. (2019). Public Cloud Soaring To $\$ 331 \mathrm{~B}$ by 2022 According to Gartner, Forbes. Available at: <https://www.forbes. com/sites/louiscolumbus/2019/04/07/publiccloud-soaring-to-331b-by-2022-according-togartner/?sh=1480d1de5739>, last accessed: $01 / 26 / 2021$.

Demirkan, H. \& Delen, D. (2013). Leveraging the Capabilities of Service-Oriented Decision Support Systems: Putting Analytics and Big Data in Cloud, Decision Support Systems, 55(1), 412-412.

Depeige, A. \& Doyencourt, D. (2015). Actionable Knowledge as A Service (AKaaS): Leveraging Big Data Analytics in Cloud Computing Environments, Journal of Big Data, 2(1), 1-16. DOI: 10.1186/ s40537-015-0023-2

Dignan, L. (2019). Top Cloud Providers 2019: AWS Microsoft Azure, Google Cloud; IBM Makes Hybrid Move; Salesforce Dominates SaaS. Available at: $<$ https://www.zdnet.com/article/top-cloud-providers2019-aws-microsoft-azure-google-cloud-ibm-makeshybrid-move-salesforce-dominates-saas/>, last accessed: 01/26/2021.

Eskelinen, T., Rsnen, T., Santti, U., Happonen, A. \& Kajanus, M. (2017). Designing A Business Model for Environmental Monitoring Services Using Fast MCDS Innovation Support Tools, Technology Innovation Management Review, 7(11), 36-46.

Filip, F. G. (2020). DSS - A Class of Evolving Information Systems. In Dzemyda, G., Bernatavičienè, J. \& Kacprzyk, J. (eds.), Data Science: New Issues, Challenges and Applications. Studies in Computational Intelligence, vol 869. Springer, Cham. DOI: 10.1007/978-3-030-39250-5 14

Filip, F. G., Zamfirescu, C. B. \& Ciurea, C. (2017) Computer-Supported Collaborative Decision-Making. Springer International Publishing. Print ISBN978-3319-47219-5.

Guo, Z. X., Ngai, E., Yang, C. \& Liang, X. (2015). An RFID-based Intelligent Decision Support System Architecture for Production Monitoring and Scheduling in A Distributed Manufacturing Environment, International Journal of Production Economics, 159, 16-28.

Guo, Z. X., Wong, W. K. \& Guo, C. (2014). A CloudBased Intelligent Decision-Making System for Order Tracking and Allocation in Apparel Manufacturing, International Journal of Production Research, 52(4), 1100-1115.

Gupta, N., Ahuja, N., Malhotra, S., Bala, A. \& Kaur, G. (2017). Intelligent Heart Disease Prediction in Cloud Environment Through Ensembling, Expert Systems, 34(3): e12207. DOI: 10.1111/exsy.12207

Heilig, L., Lalla-Ruiz, E. \& Vo, S. (2017). Port-IO: An Integrative Mobile Cloud Platform for Real-Time
Inter-Terminal Truck Routing Optimization, Flexible Services and Manufacturing Journal, 29(3-4), 504534. DOI: 10.1007/s10696-017-9280-Z

Helo, P. \& Hao, Y. (2017). Cloud Manufacturing System for Sheet Metal Processing, Production Planning \& Control, 28(6-8), 524-537. DOI: 10.1080/09537287.2017.1309714

Hill, A. \& Böse, J. W. (2017). A Decision Support System for Improved Resource Planning and Truck Routing at Logistic Nodes, Information Technology and Management, 18, 241-251. DOI: 10.1007/s10799016-0267-3

Irvine, M. (2012). IBM Cloud Offering Decoder. Available at: $<$ https://www.ibm.com/blogs/cloudcomputing/2012/05/23/the-ibm-cloud-offeringdecoder/>, last accessed: 01/26/2021.

Jayalakshmi, M. \& Gomathi, V. (2018). Pervasive health monitoring through video-based activity information integrated with sensor-cloud oriented context-aware decision support system, Multimedia Tools and Applications, 79, 3699-3712. DOI: 10.1007/ s11042-018-6716-8

Kaparthi, S. \& Power, D. J. (2002). Spreadsheets. In Bidgoli, H. (ed. in chief), Encyclopedia of Information Systems. Academic Press.

Kumar, A., Shankar, R., Choudhary, A. \& Thakur, L. S. (2016). A Big Data MapReduce Framework for Fault Diagnosis in Cloud-Based Manufacturing, International Journal of Production Research, 54(23), 7060-7073. DOI: 10.1080/00207543.2016.1153166

Lauras, M., Benaben, F., Truptil, S. \& Charles, A. (2015). Event-Cloud Platform to Support DecisionMaking in Emergency Management, Information Systems Frontiers, 17(4), 857-869. DOI: 10.1007/ s10796-013-9475-0

Lee, C. K. H. (2017). A GA-based Optimisation Model for Big Data Analytics Supporting Anticipatory Shipping in Retail 4.0, International Journal of Production Research, 55(2), 593-605. DOI: 10.1080/00207543.2016.1221162

Lee, C. K. H., Choy, K. L., Ho, G. T. S. \& Lin, C. (2016). A Cloud-Based Responsive Replenishment System in A Franchise Business Model Using A Fuzzy Logic Approach, Expert Systems, 33(1), 14-29. DOI: 10.1111/exsy. 12117

Liu, F., Tong, J., Mao, J., Bohn, R. B., Messina, J. V., Badger, M. L. \& Leaf, D. M. (2011). NIST Cloud Computing Reference Architecture. Available at: $\quad<$ https://www.nist.gov/publications/nist-cloudcomputing-reference-architecture $>$. DOI: 10.6028/ NIST.SP.500-292

Lucas, M. (2017). CW@50: Data Storage Goes From \$1m to 2 Cents Per Gigabyte. Available at: 
$<$ https://www.computerworld.com/article/3182207/ cw50-data-storage-goes-from-1m-to-2-cents-pergigabyte.html>, last accessed: 01/26/2021.

Mackay, E. B., Wilkinson, M. E., Macleod, C. J. A., Beven, K., Percy, B. J., Macklin, M. G., Quinn, P. F., Stutter, M. \& Haygarth, P. M. (2015). Digital Catchment Observatories: A Platform for Engagement and Knowledge Exchange Between Catchment Scientists, Policy Makers, And Local Communities, Water Resources Research, 51(6), 4815-4822. DOI: 10.1002/2014WR016824

Massey, A. P. (2008). Collaborative Technologies. In Burstein, F. \& Holsapple, C. (eds.), Handbook on Decision Support Systems, Vol. 17. New York: Springer-Verlag.

Mell, P. \& Grance, T. (2009). The NIST Definition of Cloud Computing, Technical Report 15. National Institute of Standards and Technology, Information Technology Laboratory.

Mercier-Laurent, E., Rousseaux, F. \& Haddad, R. (2018). Preventing and Facing New Crisis and Risks in Complex Environments, International Journal of Management \& Decision Making, 17(2), 148-170. DOI: 10.1504/IJMDM.2018.092570

NCTA (2019). The Shrinking Cost of a Megabit. Available at: < https://www.ncta.com/whats-new/theshrinking-cost-of-a-megabit $>$, last accessed: 01/26/2021.

O’Flaherty, B. \& Heavin, C. (2015). Positioning Predictive Analytics for Customer Retention, Journal of Decision Systems, 24(1), 3-18.

Peng, T. \& Shiang, W. (2014). Developing A Cloud Carbon Footprint Decision Support System for Supply Chain, International Journal of Electronic Business Management, 12(3), 200-213.

Pick, J. B., Turetken, O., Deokar, A. V. \& Sarkar, A. (2017). Location Analytics and Decision Support: Reflections on Recent Advancements, Decision Support Systems, 99(1-8). DOI: 10.1016/j. dss.2017.05.016

Power, D. J. (2001). Supporting Decision-Makers: An Expanded Framework. In Harriger, A. (ed.), eProceedings of the 2001 Informing Science Conference, Krakow, Poland, ISSN 1535-0703 (pp. 431-436). DOI: $10.28945 / 2384$

Power, D. J. (2012). What Are Benefits of Decision Support Applications in The Cloud?, Decision Support News. Available at: <http://dssresources.com/ faq/index.php?action=artikel\&id=243>, last accessed: 01/26/2021.

Power, D. J. (2013). Mobile Decision Support and Business Intelligence: An Overview, Journal of Decision Systems, 22(1), 4-9.
Power, D. J. (2018). What Is the Evolution of Decision Support and Analytics Architectures? Available at: <https://dssresources.com/faq/index. php?action $=$ artikel\&id $=449>$, last accessed: 01/26/2021.

Power, D. J., Heavin, C., Mcdermott, J. \& Daly, M. (2018). Defining Business Analytics: An Empirical Approach, Journal of Business Analytics, 1(1), 40-53. DOI: $10.1080 / 2573234 X .2018 .1507605$

Power, D. J. \& Kaparthi, S. (1998). The Changing Technological Context of Decision Support Systems. In. Berkeley, D., Widmeyer, G. R., Brezillon, P. \& Rajkovic, V. (eds.), Context-Sensitive Decision Support Systems. London: Chapman and Hall.

Rupnik, R., Kukar, M., Vračar, P., Košir, D., Pevec, D. \& Bosnić, Z. (2019). AgroDSS: A decision support system for agriculture and farming, Computers Electronics Agriculture, 161, 260-271. DOI: 10.1016/j. compag.2018.04.001

Russell, S., Yoon, V. \& Forgionne, G. (2010). CloudBased Decision Support Systems and Availability Context: The Probability of Successful Decision Outcomes, Information Systems and E- Business Management, 8, 189-205. DOI: 10.1007/s10257-0100126-4

Siddike, M. A. K., Spohrer, J., Demirkan, H. \& Kohda, J. (2018). People's Interactions with Cognitive Assistants for Enhanced Performances. In Proceedings of the $51^{\text {st }}$ Hawaii International Conference on System Sciences (pp. 1640-1648).

Singh, S. K. (2017). Conceptual Framework of a Cloud-Based Decision Support System for Arsenic Health Risk Assessment, Environment Systems \& Decisions, 37(4), 435-450. DOI: 10.1007/s10669017-9641-x

Sprague Jr., R. H. \& Carlson., E. D. (1982). Building Effective Decision Support Systems. Englewood Cliffs, N.J.: Prentice-Hall, Inc.

Thomas, B. G., Bollapragada, S., Akbay, K., Toledano, D., Katlic, P., Dulgeroglu, O. \& Yang, D. (2013). Automated Bed Assignments in A Complex and Dynamic Hospital Environment, Interfaces, 43(5), 435-448.

Tsiligiridis, T., Pontikakos, C. \& Perdikis, D. (2014). Architectural Issues of a Location-Aware System Applied in Fruit Fly E-Monitoring and Spraying Control, AGRIS on-Line Papers in Economics and Informatics, 6(4), 195-207.

Wan, J., Tang, S., Hua, Q., Li, D., Liu, C. \& Lloret, J. (2018). Context-Aware Cloud Robotics for Material Handling in Cognitive Industrial Internet of Things, IEEE Internet of Things Journal, 5(4), 2272-2281. DOI: 10.1109/JIOT.2017.2728722 